\title{
REMOTE\#RESEARCH - A Telediagnosis Assistance System for Multiple-Lead Electrocardiography
}

Paulo Bentes ( $\square$ paulobentes@gmail.com )

Universidade Federal do Para https://orcid.org/0000-0002-3832-660X

Jurandir Nadal

Universidade Federal do Rio de Janeiro

Software

Keywords: telemedicine, electrocardiography, telediagnosis, remote processing

Posted Date: September 22nd, 2020

DOI: https://doi.org/10.21203/rs.3.rs-75454/v1

License: (c) (i) This work is licensed under a Creative Commons Attribution 4.0 International License. Read Full License 
REMOTE\#RESEARCH - A Telediagnosis Assistance System for Multiple-Lead

Electrocardiography

\section{Authors:}

Paulo César Lucena Bentes ${ }^{1, *}$, Jurandir Nadal ${ }^{2}$

${ }^{1}$ Instituto de Tecnologia - Universidade Federal do Pará, Belém, Brasil.

${ }^{2}$ Instituto Alberto Luiz Coimbra de Pós Graduação e Pesquisa de Engenharia - Universidade Federal do Rio de Janeiro, Rio de Janeiro, Brasil.

*Correspondence author: paulobentes@ufpa.br (Paulo César Lucena Bentes).

There is no conflict of interest in this paper. 


\section{$\underline{\text { Abstract }}$}

Background: The diffusion of telemedicine opens up a new perspective for the development of technologies furthered by Biomedical Engineering. In particular, herein we deal with those related to telediagnosis through multiple-lead electrocardiographic signals.

Objectives: This study focuses on the proof-of-concept of an internet-based telemedicine system as a use case that attests to the feasibility for the development, within the university environment, of techniques for remote processing of biomedical signals for adjustable detection of myocardial ischemia episodes.

Methods: At each signal lead, QRS complexes are detected and delimited with the J-point marking. The same procedure to detect the complex is used to identify the respective $T$ wave, then the area over the $S T$ segment is applied to detect ischemia-related elevations. The entire system is designed on web-based telemedicine services using multiuser, remote access technologies, and database.

$\underline{\text { Results: }}$ The measurements for sensitivity and precision had their respective averages calculated at $11.79 \%$ and $24.21 \%$ for the leads of lower noise. The evaluations regarding the aspects of user friendliness and the usefulness of the application, resulted in $88.57 \%$ and $89.28 \%$ of broad or total acceptance, respectively.

Conclusions: They are robust enough to enable scalability and can be offered by cloud computing, besides enabling the development of new biomedical signal processing techniques within the concept of distance services, using a modular architecture with collaborative bias.

Keywords: telemedicine, electrocardiography, telediagnosis, remote processing.

\section{Background}

The widespread use of personal computers and the Internet has created favorable conditions for the practice of telemedicine, which has spread throughout European countries, Australia, the United 
States, and Canada with popular acceptance. This practice can bring indisputable benefits to developing countries, as it contributes to the universalization of access to health, especially in Brazil where the statistical comparison between local diagnoses and others made by a specialized team in a telemedicine center showed that cardiovascular emergencies are poorly diagnosed, leading to high mortality, mainly regarding to acute ischemia and ventricular tachycardia ${ }^{1}$. Nevertheless, there is evidence of reduced in-hospital mortality when strategies involving telemedicine ${ }^{2}$ are used, and whose massification may be very beneficial to Brazil, given its demographic profile indicating the concentration of doctors within 39 Brazilian cities with over 500,000 inhabitants, which together make up $30 \%$ of the population, and concentrate $60 \%$ of the practitioners in the country ${ }^{3}$. This pattern of inequality in allocation is generally exacerbated when considering the allocation of specialists. Specialist care services are offered in public outpatient units on a regional scale. In these units, medical consultations are held by specialists, and diagnosis and supportive therapeutic services are also offered. However, that is where the most significant bottlenecks occur since the system has been organized based on the logic of procedure offerings, disregarding the epidemiological profile of the population. The impacts of such bottleneck postpone the treatment of diseases and may reflect on the increasing demand for high complexity services, with severe damage to the health of the population and the public treasury ${ }^{4}$.

In Brazil, the Support Program for Institutional Development of the Unified Health System (PROADI-SUS) has implemented telemedicine services focused on urgent and emergency cases, in which high-tech hospitals assist health units in remote locations. Experience has shown that the success in medical practices via telemedicine depends on the establishment of clinical protocols for diagnosis and treatment that include such technology ${ }^{5}$, besides the training of the professionals involved. In general, the systems currently in operation are based on the intervention of a specialist on duty and able to provide remote assistance. 
However, the Federal Council of Medicine of Brazil requires that a physician must examine the patient ${ }^{6}$. Thus, all care provided through telemedicine must be accompanied by a physician close to the patient, except in cases of urgency or emergency and attested inability.

On the other hand, significant advances of autonomous decision support systems favor the development of remote service resources that enable the analysis of patient data, signals and images automatically, aiming to promote the accuracy and promptness of care. The development of computational techniques for early detection of ischemic episodes in electrocardiographic signals (ECG) has been relevant in biomedical research 78910111213 , and this study aims to forecast the conception of a system upon which new computational methods to assist telediagnosis for electrocardiographic exams can be built, in the academic environment, by engineering students.

A telediagnosis assistance system may use the so-called Cloud Computing, described by the National Institute of Standards and Technology (NIST) as a model capable of enabling, on-demand with its measurement, ubiquitous access to a scalable and shared set of configurable computational resources ${ }^{14}$, where software aimed at health services can be implemented, including those for electrocardiographic analysis.

To do so, both bibliographic and apocryphal documents - obtained via the Internet - were used, since many details of web-based services are not present in the bibliography offered by its developers or other authors that address the theme. It was possible to integrate the technologies involved in a single tool only by understanding their operation.

Thus, the present study aims the development of a system designed for remote processing, that can be continued in the academic environment, of multiple-lead electrocardiograms to present the proof-of-concept for the adjustable detection of heartbeat and identification of acute ischemic attacks and potential acute myocardial infarction.

\section{$\underline{2 \text { Implementation }}$}

\subsection{System Architecture}


In order to develop the application and test the Internet availability, a MacBook Pro laptop equipped with an Intel Core i5-2435M four-core CPU @ 2.4GHz processor and 4 GB of volatile memory, with the 64-bit Ubuntu 17.04 Linux operating system was used, where Eclipse Java EE was installed as Integrated Development Environment (IDE) for Web developers, Oxigen version, with update 4.7.0. The Wildfly 10 Application server, integrated with MySQL through mysql-connectorjava-5.1.38 was also used.

For the tests, we used files from the European ST-T Database ECG database, available online by Physionet ${ }^{15}$, converted using the rdsamp command. This converts the data file to a vector sequence for $\mathrm{x}$ and $\mathrm{y}_{1}, \mathrm{y}_{2}, \ldots, \mathrm{y}_{\mathrm{n}}$ (where $\mathrm{n}$ is the number of leads present in the file) in string format, and is part of the WFDB (WaveForm DataBase) program package provided by the Physionet website itself.

The use case diagram, shown in Fig. 1, predicts filtering, graph generation, signal reference and metadata extractor, classifier and report generator of events found, all in accordance with the architecture required for processing module implementation of signals capable of storing both the original signals and their metadata and reports.

Figure 1 here.

The Application Programming Interface (API) for Java EE (Enterprise Edition) language, an accessible development platform with extensive and available query documentation, was used. It supports component-based frameworks such as Java Database Connectivity (JDBC) API, Remote Method Invocation (RMI), Web Services, Extensible Markup Language, and others, able to absorb many of the available data mining technologies ${ }^{16}$. Such an application is available via a Wildfly server $^{1}$ integrated with a relational MySQL database, which needs to be available via the World Wide Web (WWW), commonly called the Web.

When a relational database is used, it is necessary to think how their tables and their interrelationships are constituted in the entity relationship model ${ }^{17}$, which joins the tables through 
foreign keys corresponding to the identifiers of the related tables. During storing in a database, differences between entity-relationship model and object orientation, called Object-Relational Impedance, need to be addressed in the system design when using JDBC, which consists of several classes and interfaces that provide database access employing drivers supported by the Database Manager System (DBMS). Such adjustments need to be made through classes that instantiate Data Access Objects $(D A O)$, which aim to deal with data persistence.

The required adjustment to overcome the Object-Relational Impedance made in $D A O$ can be enabled by classes that perform Object Relational Mapping (ORM), also referred to as ORM frameworks such as EclipseLink, OpenJPA, and Hibernate. They all work under the Java Persistence API (JPA) specification, which made the ORM libraries compatible. Once the database connection to Wildfly settings (in the standalone-full.xml file) has been mapped, a new database table when mapping a new entity is not needed ${ }^{18}$.

Web development in Java is class-based, and server-side Servlet calls mapped from a virtual address pattern (Uniform Resource Locator - URL) provide some functionality to be loaded into memory. Yet, the insertion of the HTML code inside the Java code to allow the visualization of the results is an inversion difficult to be maintained. Hence, Java Server Pages (JSP), builders of HTML pages also called View - are used and may have Java codes, as well as attributes loaded from the Servlet, which performs the desired tasks, while JSP are responsible for displaying the result, thus correcting the inversion.

Servlet may also delegate a portion of its activities to other classes known as Model, which are responsible for performing functional requirements of the system. Such Servlet is now known as Controller and is responsible for receiving user requests, instantiating the corresponding objects and passing them to Model, creating the Model-View-Controller (MVC) model that can be aided by tools called MVC Frameworks. Java Server Faces (JSF), one of these frameworks ${ }^{19}$, was implemented through an open source product: Primefaces. The Fig. 2 shows the activity diagram for activities of ischemic episode search from the representative areas of each beat. 
Figure 2 here.

The system has a web access portal, accessible from desktop browsers, tablets, or smartphones. The portal has a menu to access the tool-related activities and an identification and motivation page of its authors, as well as a brief tutorial of the capabilities of the tool installed.

The system forecasts a prior registration of the exam to accept the transfer of the corresponding electrocardiographic file, not necessarily allowing it to keep a copy of the file on the server side. If prompted to store data in the database from a non-existent file, the user name is required to perform the file transfer, thus simplifying the process maintenance.

In order to manipulate the original electrocardiographic data, it is first necessary to store the analysis intervals in the database. This will be available for consultation at any time until deleted by the user. This capability is important for the development platform of new biomedical signal processing methods, as it allows to separately analyze different events present in the same file and their impacts on the proposed processing method.

The system currently enables to perform high-pass and low-pass filtering on electrocardiographic signals, as well as to calculate characteristic areas of the $S T$ segment to detect the presence of ischemic episodes. When choosing the latter option, the user has the application store the value of the calculated areas, which can be visualized by graphs for the range, as shown in Fig. 3A.

Figure 3 here.

Once the application finds ischemia episodes through the area variation, the user can choose to display the results. In this case, the user is directed to a page containing the list of ischemic episodes stored in the database for the respective interval, as shown in Fig. 3B. It is also possible to 
show the original electrocardiogram graphs of any segment within the search range, as shown in Fig. 3C.

The impairments in outpatient procedures in the removal of the corneal extract for the preparation of the electrocardiographic exam cause variations in the distribution of charges between the electrode / electrolyte and the patient's skin, leading to changes in the potential difference measured between the electrodes used during the exam. This is called a motion artifact and results in a base deviation during biopotential collection as found in derivatives $I I I$ and V3 in Fig. 3C, where can be observed that derivative $I I I$ has its base close to $-0.5 \mathrm{mV}$, while in derivative $\mathrm{V3}$ the base is about $1.7 \mathrm{mV}$ and both show deviations around these biopotentials. It is desirable to eliminate such deviations or at least to attenuate them as much as possible, and only then perform the electrocardiographic signal processing.

The initial objective of various forms of ECG analysis is to detect QRS complexes, typically the sequence of the most prominent signal waves that represent the electrical activity of ventricular depolarization ${ }^{20}$ and then to take them as reference points. The proposed detection uses the weighted least squares technique ${ }^{21}$.

Given the linear regression:

$Y_{r}=b_{w 1} \cdot X+b_{w 0}$

the angular coefficient $\left(\mathrm{b}_{\mathrm{w} 1}\right)$ is obtained by

$$
b_{w 1}=\frac{\sum w_{i} \cdot X_{i} \cdot Y_{i}-\frac{\sum w_{i} \cdot X_{i} \cdot \sum w_{i} \cdot Y_{i}}{\sum w_{i}}}{\sum w_{i} \cdot X_{i}^{2}-\frac{\left(\sum w_{i} \cdot X_{i}\right)^{2}}{\sum w_{i}}}
$$

and the linear coefficient $\left(\mathrm{b}_{\mathrm{w} 0}\right)$ is

$$
b_{w 0}=\frac{\sum w_{i} \cdot Y_{i}-b_{w 1} \cdot \sum w_{i} \cdot X_{i}}{\sum w_{i}}
$$

for which a rule of weight distribution was used ${ }^{22} \mathrm{~W}_{\mathrm{i}}$ given by 
$w_{i}=\left(1-\left|\frac{X-X_{i}}{d(X)}\right|^{3}\right)^{3}$

where $d(X)$ is the distance between $X$ and the furthest point from $X$ within a filtering window of odd length $L$ along the abscissa. Each central point of the sliding window should then have their ordinate repositioned (Yr) according to the equation of the line of equation (1), where $X$ will be given by the sequential samples of the raw signal.

The angular coefficient $b_{w 1}$ of each repositioned point gives its derivative. Curves in Figs. 4A,B illustrate the MLIII lead of the original ECG and the isoelectric curve obtained from an estimate from a low-pass filter with $L=249$, respectively. However, the entire analysis procedure can be applied to each of the available ECG lead. Curve in Fig. 4C composes the graph with the repositioned points from a filtering window with $L=39$. It is important to point out that the filtering window should slide over the entire sample analyzed and the processing point is in the center of the window ${ }^{23}$ to prevent phase distortion. The resulting signal consists of a polynomial approximation, as proposed by the Savitzky-Golay method ${ }^{24}$, equivalent to the convolution between the original signal and the impulse response, that is, a low-pass filter.

Figure 4 here.

When the low-pass filter of the resulting signal from the original signal is subtracted, a high-pass filter is obtained, the remainder of which is filtered again into a low-pass filter with $L=9$ to attenuate the remaining white noise. The signal resulting from such filtering is representative for high frequency signals, for it preserves the potential gradient values near the signal peaks, while being normalized to the biopotential values, and the base deviations are attenuated. Curve in Fig. 4D illustrates the result obtained after these filtrations, while curve in Fig. $\mathbf{4 E}$ is given by the angular coefficient $b_{w 1}$, and represents the signal derivative in Fig. 4D. 
In order to detect the $Q R S$ complex, a vertical histogram was implemented ${ }^{25}$, where each value corresponds to the number of samples within a sliding window that should be selective for the typical slopes of the $Q R S$ complex. The size of the window should be calculated according to the informed sampling rate for the electrocardiographic signal, and should correspond to the odd number of samples comprising $0.07 \mathrm{~s}$ of signal, which corresponds to the shortest length expected for the $Q R S$ complex ${ }^{26}$.

After submitting the entire range of the analyzed signal to the sliding window, a new signal representing the histogram is obtained, as shown in Fig. 4F. This must be submitted to a new lowpass filtering with $L=15$ to improve the expectation of unique peaks for each $Q R S$ complex, resulting in Fig. 4G. Afterwards, the positions of the complexes are established by signal tests of the derivative value between neighboring or near points within sliding windows of three samples, whose value is positive for derivatives of the same signal and negative for derivatives of opposite signals, showing thus the existence of a peak in the histogram signal and, consequently, position for the QRS complex, as illustrated by curve in Fig. $\mathbf{4 H}$. Consecutive zeros in the histogram signal indicate that the interval comprised by the QRS complex has ended and thus the beginning and end of the complex can be marked. The Fig. 4I is the representation of the composition of these findings after proper approximation match and precedence.

Similarly, by using a permissive threshold for the characteristic $T$ wave slopes on Fig. $\mathbf{4 E}$, curve in Fig. 4J is obtained, which after being filtered presents as Fig. 4K, whose derivatives result in Fig. 4L. When the findings near the points assigned to the $Q R S$ complex, that is, within a given range, are eliminated, positions can be assigned to both $T$ waves and all other waves captured in the same procedure, as shown in Fig. 4M. The algorithm comprises an elimination process for the points corresponding to $P$ waves, typically found before the $Q R S$ complex, and admits only one $T$ wave at each beat, promoting the elimination of findings corresponding to a feasible $U$ wave. Thus, Fig. 4N is obtained, where only $T$ wave survives. 
Once $T$ waves are found, they need to be paired with the $Q R S$ complexes, which can be done by proximity and by the fact that such wave is always a consequence of the existence of a $Q R S$ complex. After being paired, the position of the endpoint of the $Q R S$ complex ( $J$ point) and the position found for the $T$ wave are used to determine $S T$ segment, whose absolute area is calculated.

The original electrocardiographic signal (Fig. 4A) is used for this purpose, yet it is necessary to refer to the signal as isoelectric (Fig. 4B), also referred to as the base signal. Such heights are combined with the time taken from the sampling rate to calculate the areas contained in the interval that, when added, provide the representative area of each beat. Each one of these calculated areas should be stored linked to the corresponding beat, the reference of which is the equivalent $T$ wave position, and then representative signals of the areas are obtained, as shown in Fig. 40. Due to the high variability, even between neighboring positions, each signal of this type needs to be submitted to a new low-pass filter, whose window has been empirically set to the length of $L=49$, which smoothes the curves and results in signals such as those shown in Fig. 4P.

Curves in Fig. 5A,B represent the values of the representative areas found and their low-pass filtering with $L=49$ for the persisted interval of $2000 \mathrm{~s}$ to $2300 \mathrm{~s}$, that is, these curves represent the extension of the curves shown by curves in Fig. 40,P. Both the representative values of the areas and the respective angular coefficients representative of their derivatives, as shown by Fig. 5C, are available after filtering.

Figure 5 here.

Similar to previous histograms, a sliding window is used to increment when derivatives exceed a certain threshold, and decrement when they have a negative value. Following the same rules as previously described, a new vertical histogram signal can be obtained (Fig. 5D) from a predetermined threshold, used to ensure that the slope is sufficient to be considered as the slope of ischemia. Then, a new low-pass filtering with $L=35$ is used over the histogram signal (Fig. 5E), 
whose maximum is located near the center of the rising phase of the area curve (Fig. 5A), mainly if a new low-pass filtering with $L=35$ is used over the histogram signal (Fig. 5B). The derivative of the filtered histogram is obtained (Fig. 5F) and anew a small three-position window is used to enforce the signal rule that will point to a negative value by means of peaking the filtered histogram signal, and a possible occurrence of ischemia can be identified and recorded in the database and be retrieved, as shown in Fig. 3B.

\section{$\underline{\text { 2.2 Evaluation of user friendliness and usefulness of the application }}$}

From the adaptation of the model used in the evaluation structure as a support tool for the "Systematic Review process” ${ }^{27}$ that applies the Technology Acceptance Model -TAM ${ }^{28}$, evaluative tests were conducted under the aspects of user friendliness and usefulness of the application, with the participation of engineering students carrying out method implementation tests based on the goal / question / metric ${ }^{29}$ paradigm. The model foresees the presentation, for the evaluators, by the questions presented in Table 1, relating to the evaluated aspects, whose answers are represented by an ordinal scale of decreasing value in Table 2.

Table 1 here.

Table 2 here.

The evaluators consisted of seven students enrolled in engineering courses, for whom seven archives of the European ST-T Database (e0111, e0126, e0154, e0413, e0509, e0605) were made available, in addition to the reference positions for ischemic events provided in the same database, permitting a comparison of the result of their interactions with the tool and therefore allowing for the ability to evaluate the usefulness of the application during the refinement of the method through the adjustment of the parameters given by the slope applied to the curve illustrated in Fig. 5C, and 
by the size of the formation window in the histogram presented in Fig. 5D. Table 3 informs the percentage for each answer presented during the evaluation.

Table 3 here.

\section{$\underline{3 \text { Results }}$}

\subsection{Sensitivity and Precision}

All the files of the European ST-T Database were used to conduct a study on sensitivity and precision, adjusting the parameters given by the minimum slope $\left(b_{w 1}=0.25\right)$ applied on the curve of Fig. 5C, and by the window size $(L=61)$ of the formation of the histogram represented by Fig. 5D. Regarding the lower noise lead - put in the files - the average sensitivity was $11.79 \%$, while the average precision was $24.21 \%$. For the higher noise lead, the measurements were $11.54 \%$ and $25.61 \%$, respectively. These results were very close to the those obtained when the detection of changes in a ST segment during a hospital screening was ascertained-roughly $12 \%{ }^{30}$.

\section{$\underline{3.2}$ User friendliness and usefulness of application}

The results display the evaluators' satisfaction regarding user friendliness and usefulness of the application, since $88.57 \%$ of the questions relating to user friendliness and $89.28 \%$ relating to usefulness were responded to with total or broad acceptance of the application. However, such satisfaction is relativized at the intersection between these two aspects represented by Q4 (which was partially accepted in $28.57 \%$ of the answers), indicating that to perform the refinement of the method there was some difficulty in the use of the application. This result points out that the application is promising in its purpose, but also the need for greater automation in the refinement process of the method of searching for ischemic events proposed.

\section{Discussion}


The onscreen work exploited and implemented technologies that allow the processing of multiplelead electrocardiographic exams in the search for ischemic episodes based on a web service offered by the Internet. This work did not seek to address the effectiveness of the implemented ischemic episode detection method, and filtering and detection techniques were used only to exemplify a complete processing cycle for the system, focusing on low computational cost and data persistence.

This study contributes to the architecture of a system that can be gradually expanded by the addition of new methods of electrocardiographic signal processing in the search for ischemic episodes, while providing an experience that can be implemented in telemedicine from a Cloud Computing perspective $^{31} 32$.

Virtualization, typical of Cloud Computing, once considered a performance bottleneck, now has the right hardware and techniques for its implementation with the advantages of isolation and encapsulation that enable to suppress the influences of other systems and the use of load balancing techniques and high availability. At the same time, it allows hardware sharing offering a wider range of services ${ }^{33}$.

Despite its monolithic nature, the developed application is capable of receiving other methods of processing electrocardiographic signals, which may constitute a library. Therefore, this project may contribute to enable the development of innovations in the area of biomedical signal processing.

In addition to the methods of processing biomedical signals, the application itself allows improvements, including the monolithic structure, which can be rethought for a microservice architecture ${ }^{34}$, which retains self-reliance characteristics and distribute the parts of the business rule. Independent developers can implement it in different languages and data storage technologies, and for these same reasons it also has greater complexity in its design, but also allows to be implemented under Wildfly ${ }^{35}$.

In the search for referential in the signals, filters were applied to isolate the signal of interest from that caused by motion artifacts, being imperative to subject the signal to a filtering process to 
highlight the representative signals of both the $Q R S$ complex and the $T$ wave. The main advantage of using the least-squares method to obtain an equivalent polynomial signal, as proposed by Savitzky-Golay, is that the filtered signal does not undergo phase distortion ${ }^{36}$, which occurs when filtering occurs in the frequency domain ${ }^{37}$. Furthermore, when a tiny window is used $(L=9)$, not even the value of the original derivatives is affected ${ }^{38}$, thus preserving the values of the moments near the inflection point ${ }^{39}$.

Once the position of $J$ point can be shifted to the right without negatively compromising the quality of the marker ${ }^{40}$, further care with the accuracy of taking that point is not required provided the same rule applies for all beats, for the interest lies in the measure of the growth of the value of the area bounded by this point and that which serves as the central marker of the $T$ wave, by the original signal and the curve taken as the base signal.

When a low-pass filter with $L=249$ was used, we favored the low frequency signals of the $P R$ and ST segments and obtained a signal that is very likely to be close to the isoelectric axis ${ }^{36}$. Hence, it is reasonable to consider it when taking the area between the original electrocardiographic signal and that signal considered as the base signal in the interval between the $J$ point and the $T$ wave, thus concluding the boundary taken for the areas peculiar to beats.

In the graph (Fig. 3A), the increase of the representative area of each beat in the two leads present in the signal is clear, which could be understood as a sign of the occurrence of an ischemic episode. A histogram assembled from specific rules to demonstrate the expected behavior was used to perform the episode occurrence time followed by its database storage, which can be consulted at any time.

The procedure to detect ischemic episode is independent of the fact that the ST segment shows depression or elevation, for both cases implies an increase in the measured area. Nevertheless, a simple inspection of the segment where the increase in area values occurred may indicate cases of segment depression, usually observed in ischemia episodes. Segment elevation is unusual, yet 
usually corresponds to a more severe ischemia process, being present even in acute myocardial infarction.

It is expected that a Big Data ${ }^{41}$ approach, provided by Cloud Computing, will enable implementations under the concept of precision medicine, which is able to provide tailored treatments for each patient, taking into account various factors such as genetics, ethnicity or lifestyle, decreasing the rates of events with adverse outcomes ${ }^{38}$.

\section{$\underline{5 \text { Conclusions }}$}

This tool was developed with strong concern regarding its usability, modularity and scalability, being able to receive modules that include other signal processing techniques, allowing the risk stratification of critical events from electrocardiographic alterations. The system has segmentation and input data storage modules, and a graphic module for output representation, filtering modules and other preprocesses as well as detection and classification. Signals entirely remain in a relational database, allowing the use of a wide range of adjustable techniques without facing severe memory or processing limitations. Moreover, other modules may also be included to allow preprocessing from the data file itself to accommodate features of any particular technique requiring such architecture, including the formation of mixed solutions with simultaneous exploitation of the database.

The versatility of the proposed system is quite attractive, together with the possibility to quickly implement and test new techniques to automate the search for ischemic episodes through telemedicine practice. This project can grow, transform and provide the researcher with new features, making him/her a system actor, besides being the user.

The readiness of implementation of new persistence entities in the database, which can be easily related to the entities that carry the input data, makes this tool very attractive in the search of 
biomedical signal processing techniques, especially for those seeking to collaborate with the management of health resources to promote the improvement of medical care for the population.

\section{List of abbreviations}

Application Programming Interface (API); Data Access Objects (DAO); Database Manager System (DBMS); National Institute of Standards and Technology (NIST); HyperText Markup Language (HTML); Java Server Faces (JSF); Java Server Pages (JSP); Java Database Connectivity (JDBC); Java Persistence API (JPA); Model-View-Controller (MVC); Object Relational Mapping (ORM); Remote Method Invocation (RMI); Support Program for Institutional Development of the Unified Health System (PROADI-SUS); Uniform Resource Locator (URL); WaveForm DataBase (WFDB); World Wide Web (WWW)

\section{$\underline{\text { Availability and requirements }}$}

Project name: remote\#research

Project home page: https://sourceforge.net/projects/remoteresearch/

Operating system(s): Platform independent

Programming language: Java

Other requirements: Wildfly 10

License: Creative Commons - Attribution 4.0 International

\section{Declarations}

Ethics approval and consent to participate

Not applicable

\section{Consent for publication}

Not applicable

Availability of data and materials 
The datasets analysed during the current study are available in European ST-T Database, available online by Physionet repository, https://physionet.org.

\section{Competing interests}

JN received financial support from the Brazilian agencies FINEP and CNPq.

\section{Funding}

Funds from FINEP and CNPq agencies were used in the final revision of the text in English.

\section{Authors' contributions}

PCLB carried out the research that gave rise to the method of processing biomedical signals, carried out the prospecting and execution of the computational techniques used, performed the tests with the signals and wrote the initial text of the article. JN guided all research and revised the entire text of the article.

\section{Acknowledgements}

This study received financial support from the Brazilian agencies FINEP and CNPq.

\section{$\underline{\text { References }}$}

1. Marcolino MS, Santos TMM, Stefanelli FC, et al. Cardiovascular emergencies in primary care: An observational retrospective study of a large-scale telecardiology service. Sao Paulo Med J. 2017;135(5):481-487. doi:10.1590/1516-3180.2017.0090110617

2. Marcolino MS, Maia LM, Oliveira JAQ, et al. Impact of telemedicine interventions on mortality in patients with acute myocardial infarction: A systematic review and meta-analysis. Heart. June 2019:heartjnl-2018-314539. doi:10.1136/heartjnl-2018-314539

3. Scheffer M, Biancarelli A, Cassenote A. Demografia Médica No Brasil 2015. São Paulo: Departamento de Medicina Preventiva da Faculdade de Medicina da USP; Conselho Regional de Medicina do Estado de São Paulo; Conselho Federal de Medicina; 2015.

4. Brito FG, Rodrigues AA de A, Filho JBD. Telemedicina como Instrumento de Soporte en la Atención Primaria a la Salud. Latin American Journal of Telehealth. 2017:155-160.

5. de Souza CHA, Morbeck RA, Steinman M, et al. Barriers and Benefits in Telemedicine Arising Between a High-Technology Hospital Service Provider and Remote Public Healthcare Units: A Qualitative Study in Brazil. Telemed E-Health. 2017;23(6):527-532. doi:10.1089/tmj.2016.0158

6. Conselho Federal de Medicina. Resolução CFM No $1931 . \quad 2009$. https://portal.cfm.org.br/index.php?option=com_content\&view=article\&id=20670:resolucao- 
cfm-no-19312009-\&catid=9:codigo-de-etica-medica-atual\&Itemid=122. Accessed February 17, 2019.

7. Rad M, Ghuchani S, Bahaadinbeigy K, Khalilzadeh M. Real Time Recognition of Heart Attack in a Smart Phone. Acta Inform Medica. 2015;23(3):151. doi:10.5455/aim.2015.23.151154

8. Tseng Y-L, Lin K-S, Jaw F-S. Comparison of Support-Vector Machine and Sparse Representation Using a Modified Rule-Based Method for Automated Myocardial Ischemia Detection. Comput Math Methods Med. 2016;2016:1-8. doi:10.1155/2016/9460375

9. Gimeno-Blanes FJ, Blanco-Velasco M, Barquero-Pérez Ó, García-Alberola A, Rojo-Álvarez JL. Sudden Cardiac Risk Stratification with Electrocardiographic Indicesâ A Review on Computational Processing, Technology Transfer, and Scientific Evidence. Front Physiol. 2016;7. doi:10.3389/fphys.2016.00082

10. Peng Z, Wang G. A Novel ECG Eigenvalue Detection Algorithm Based on Wavelet Transform. BioMed Res Int. 2017;2017:1-12. doi:10.1155/2017/5168346

11. Lines GT, de Oliveira BL, Skavhaug O, Maleckar MM. Simple T-Wave Metrics May Better Predict Early Ischemia as Compared to ST Segment. IEEE Trans Biomed Eng. 2017;64(6):1305-1309. doi:10.1109/TBME.2016.2600198

12. Wang JJ, Pahlm O, Warren JW, Sapp JL, Horáček BM. Criteria for ECG detection of acute myocardial ischemia: Sensitivity versus specificity. J Electrocardiol. 2018;51(6):S12-S17. doi:10.1016/j.jelectrocard.2018.08.018

13. Good WW, Erem B, Zenger B, Coll-Font J, Brooks DH, MacLeod RS. Temporal Performance of Laplacian Eigenmaps and 3D Conduction Velocity in Detecting Ischemic Stress. J Electrocardiol. 2018;51(6):S116-S120. doi:10.1016/j.jelectrocard.2018.08.017

14. Griebel L, Prokosch H-U, Köpcke F, et al. A scoping review of cloud computing in healthcare. BMC Med Inform Decis Mak. 2015;15(1). doi:10.1186/s12911-015-0145-7

15. Goldberger AL, Amaral LAN, Glass L, et al. PhysioBank, PhysioToolkit, and PhysioNet Components of a New Research Resource for Complex Physiologic Signals. Circulation. 2000;101(23):e215-e220. doi:10.1161/01.CIR.101.23.e215

16. Krishna V, Jose J, Suri NR. Design and development of a web-enabled data mining system employing JEE technologies. Sadhana. 2014;39(6):1259-1270.

17. Heuser CA. Projeto de Banco de Dados. 6th ed. Porto Alegre: Bookman; 2009.

18. Souza A. Java EE: Aproveite Toda a Plataforma Para Construir Aplicações. São Paulo: Casa do Código; 2015.

19. Cordeiro G. Aplicações Java Para a Web Com JSF e JPA. São Paulo: Casa do Código; 2012.

20. Francesca S, Carlo CG, Di Nunzio L, Rocco F, Marco R. Comparison of Low-Complexity Algorithms for Real-Time QRS Detection using Standard ECG Database. Int J Adv Sci Eng Inf Technol. 2018;8(2):307. doi:10.18517/ijaseit.8.2.4956

21. Kutner MH, Nachtsheim CJ, Neter J, Li W. Applied Linear Statical Models. 5th ed. New York: McGraw-Hill; 2005. 
22. García ÁL, del Castillo EF. Analysis of Scientific Cloud Computing requirements. ArXiv13096109 Cs. September 2013. http://arxiv.org/abs/1309.6109. Accessed September 28, 2018.

23. Balalaie A, Heydarnoori A, Jamshidi P. Microservices Architecture Enables DevOps: Migration to a Cloud-Native Architecture. IEEE Softw. 2016;33(3):42-52. doi:10.1109/MS.2016.64

24. Vacari I, Apolinário DR de F, Gonzales LE. Java EE Microsserviços com Wildfly Swarm. Comun Téc 127 Embrapa. 2017:11.

25. Hu X, Xiao Z, Zhang N. Removal of baseline wander from ECG signal based on a statistical weighted moving average filter. $J$ Zhejiang Univ Sci C. 2011;12(5):397-403. doi:10.1631/jzus.C1010311

26. Ojo J, Adetoyi T, Adeniran S. Removal of Baseline Wander Noise from Electrocardiogram (ECG) using Fifth-order Spline Interpolation. J Appl Comput Sci Math. 2016;10(2):9-14. doi:10.4316/JACSM.201602001

27. Hernandes, E; Zamboni, A; Thommazo, AD; Fabbri, S. Avaliação da ferramenta StArt utilizando o modelo TAM e o paradigma GQM. In: Proceedings of 7th Experimental Software Engineering Latin American Workshop. Goiânia: ESELAW’10, 2010:30-39.

28. Davis, FD. User acceptance of information technology: system characteristics, user perceptions and behavioral impacts. International Journal of Man-Machine Studies, 1993; 38(3):475-487. doi:10.1006/imms.1993.1022.

29. Basili, V; Caldiera, G; Rombach, HD. Goal Question Metric Paradigm. John Wiley \& Sons, 1994; [S.l.].

30. Drew, BJ; Pelter, MM; Lee, E; Zegre, J; Schindler, D; Fleis-Chmann, KE. Designing prehospital ECG systems for acute coronary syndromes. Lessons learned from clinical trials involving 12-lead ST-segment monitoring. Journal of Electrocardiology, 2005; 38(4):180185. doi:10.1016/j.jelectrocard.2005.06.031.

31. Murthy AS, Seelamantula CS, Sreenivas TV. Optimum short-time polynomial regression for signal analysis. Sādhanā. 2016;41(11):1245-1260.

32. Agarwal S, Rani A, Singh V, Mittal AP. Performance Evaluation and Implementation of FPGA Based SGSF in Smart Diagnostic Applications. J Med Syst. 2016;40(3). doi:10.1007/s10916015-0404-2

33. Tan X, Chen X, Ren R, et al. Real-time baseline wander removal in ECG signal based on weighted local linear regression smoothing. In: Information and Automation (ICIA), 2013 IEEE International Conference On. IEEE; 2013:453-456.

34. Dotsinsky IA, Mihov GS. Tremor suppression in ECG. Biomed Eng OnLine. 2008;7(1):29. doi:10.1186/1475-925X-7-29

36. Acharya D, Rani A, Agarwal S, Singh V. Application of adaptive Savitzky-Golay filter for EEG signal processing. Perspect Sci. 2016;8:677-679. doi:10.1016/j.pisc.2016.06.056 
37. Mitra S, Mitra M, Chaudhuri BB. Pattern defined heuristic rules and directional histogram based online ECG parameter extraction. Measurement. 2009;42(1):150-156. doi:10.1016/j.measurement.2008.05.002

37. Guyton AC, Hall JE. Tratado de Fisiologia Médica. 11th ed. Rio de Janeiro: Elsevier; 2006.

38. Al-Zoube MA, Alqudah YA. Mobile Cloud Computing Framework for Pattients' Health Data Analysis. Biomed Eng Appl Basis Commun. 2014;26(02):1450020. doi:10.4015/S1016237214500203

39. Gao F, Thiebes S, Sunyaev A. Rethinking the Meaning of Cloud Computing for Health Care: A Taxonomic Perspective and Future Research Directions. $J$ Med Internet Res. 2018;20(7):e10041. doi:10.2196/10041

40. Puelacher C, Wagener M, Abächerli R, et al. Diagnostic value of ST-segment deviations during cardiac exercise stress testing: Systematic comparison of different ECG leads and time-points. Int J Cardiol. 2017;238:166-172. doi:10.1016/j.ijcard.2017.02.079

41. Herland M, Khoshgoftaar TM, Wald R. A review of data mining using big data in health informatics. J Big Data. 2014;1(1):2. doi:10.1186/2196-1115-1-2

42. Prosperi M, Min JS, Bian J, Modave F. Big data hurdles in precision medicine and precision public health. BMC Med Inform Decis Mak. 2018;18(1). doi:10.1186/s12911-018-0719-2

\section{Legends}

Figure 1: Use case diagram.

Figure 2: Activity diagram to detect ischemic episode.

Figure 3: A - Graph of representative areas of beats for the entire range of two leads present in file e0106, displayed on a smartphone screen; B - Signs of the ischemic episode found in the interval; C - Corresponding ECG graphs, where ST segment depression is quite evident in lead V3.

Figure 4: For the MLIII lead of the ECG given in file e0106, curves A and B represent, with amplitude adjustments, the lead and the isoelectric (dashed) curve in the range between $2132 \mathrm{~s}$ and 2137 s, respectively. Then offset adjustments were also made to accommodate the curves: C - which is the result of a low-pass filter; D - after a high-pass and also a low- pass filter; E - derivative of D; F - histogram obtained from the derivative; G - result of a low-pass filter from the histogram; $\mathrm{H}$ derivative of the filtered histogram; I - representation of the $Q R S$ complexes found; $\mathrm{J}$ - a permissive limit histogram, applied to the curve E, sufficient to also find the ECG $T$ waves; $\mathrm{K}$ - $J$ low-pass filtering; L - derivative of K; M - the representation of all complexes and waves found; $\mathrm{N}$ representation of the $T$ waves found, separated from the other waves, using uniqueness, proximity and subsequence criteria; O - calculated areas for the ST segments; P - low-pass filtering interpolation curve of $\mathrm{O}$. 
Figure 5: For the MLIII lead of the ECG given in file e0106 throughout the selected range of curve A, adjusted for its amplitude, represents the calculated areas for the ST segments; B - interpolation curve when applying a low-pass filter on A. In addition to adjusting the amplitudes, an offset was also used to accommodate the curves: C - derivative of B; D - histogram obtained from C; E - lowpass histogram filtering and $\mathrm{F}$ - derivative of $\mathrm{E}$, whose reading and application of the signal rule allows to find the moment of occurrence of a possible ischemia, shown in the curve. To account for a zero crossing only histograms that reach a positive threshold are considered. 


\section{Tables}

Table 1 - Questions submitted to the evaluators. Content adapted from Hernandes, E; Zamboni, A; Thommazo, AD; Fabbri, S. Avaliação da ferramenta StArt utilizando o modelo TAM e o paradigma GQM. In: Proceedings of 7th Experimental Software Engineering Latin American Workshop. Goiânia: ESELAW’10, 2010:30-39.

\begin{tabular}{|c|c|c|}
\hline Questions & Description & Aspect \\
\hline Q1 & It was easy to use the remote\#research. & User Friendliness \\
\hline Q2 & $\begin{array}{l}\text { I was able to use the remote\#research in the way that } \\
\text { I desired. }\end{array}$ & User Friendliness \\
\hline Q3 & $\begin{array}{l}\text { I understood what happened in my interaction with } \\
\text { the remote\#research. }\end{array}$ & User Friendliness \\
\hline Q4 & $\begin{array}{l}\text { It was easy to remember how to obtain variations in } \\
\text { the output when I sought to improve the search for } \\
\text { ischemic events with remote\#research. }\end{array}$ & $\begin{array}{l}\text { User Friendliness } \\
\text { and Usefulness }\end{array}$ \\
\hline Q5 & $\begin{array}{l}\text { I consider remote\#research useful to accomplish } \\
\text { tests and improvements in the proposed signal } \\
\text { processing method. }\end{array}$ & Usefulness \\
\hline Q6 & $\begin{array}{l}\text { The remote\#research allows one to systemize the } \\
\text { search for the best parameters for the method of } \\
\text { seeking ischemic events. }\end{array}$ & Usefulness \\
\hline Q7 & $\begin{array}{l}\text { The use of the remote\#research allows for the } \\
\text { improvement of the researcher's performance during } \\
\text { the refinement of the proposed method for seeking } \\
\text { ischemic events. }\end{array}$ & Usefulness \\
\hline
\end{tabular}


Table 2 - Answers presented by the evaluators.

\begin{tabular}{|l|c|}
\hline Totally Agree & CT \\
\hline Largely Agree & CA \\
\hline Partially Agree & CP \\
\hline Partially Disagree & DP \\
\hline Largely Disagree & DA \\
\hline Totally Disagree & DT \\
\hline
\end{tabular}


Table 3 - Percentages from the answers provided by the evaluators.

\begin{tabular}{|c|c|c|c|c|c|c|}
\hline Questions & CT & CA & $\mathrm{CP}$ & $\mathrm{DP}$ & DA & DT \\
\hline Q1 & $57.14 \%$ & $42.86 \%$ & $0 \%$ & $0 \%$ & $0 \%$ & $0 \%$ \\
\hline Q2 & $71.43 \%$ & $14.28 \%$ & $14.28 \%$ & $0 \%$ & $0 \%$ & $0 \%$ \\
\hline Q3 & $71.43 \%$ & $28.57 \%$ & $0 \%$ & $0 \%$ & $0 \%$ & $0 \%$ \\
\hline Q4 & $71.43 \%$ & $0 \%$ & $28.57 \%$ & $0 \%$ & $0 \%$ & $0 \%$ \\
\hline Q5 & $100 \%$ & $0 \%$ & $0 \%$ & $0 \%$ & $0 \%$ & $0 \%$ \\
\hline Q6 & $85.71 \%$ & $0 \%$ & $14.28 \%$ & $0 \%$ & $0 \%$ & $0 \%$ \\
\hline Q7 & $71.43 \%$ & $28.57 \%$ & $0 \%$ & $0 \%$ & $0 \%$ & $0 \%$ \\
\hline $\begin{array}{c}\text { Averages } \\
\text { for user } \\
\text { friendliness }\end{array}$ & $67.14 \%$ & $21.43 \%$ & $10.71 \%$ & & & \\
\hline $\begin{array}{l}\text { Averages } \\
\text { for } \\
\text { usefulness }\end{array}$ & $82.14 \%$ & $7.14 \%$ & $10.71 \%$ & & & \\
\hline
\end{tabular}




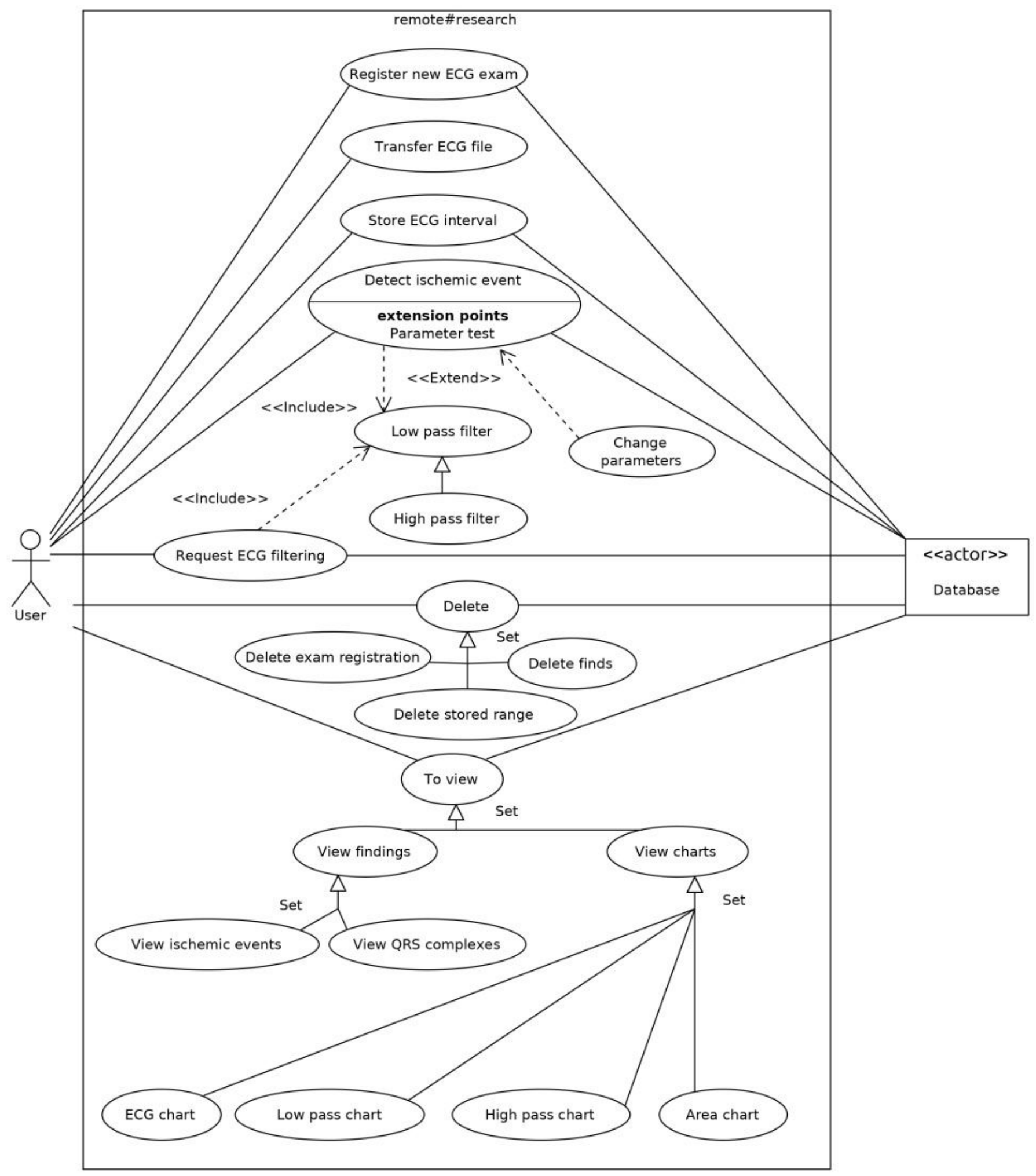

Figure 1

Use case diagram. 

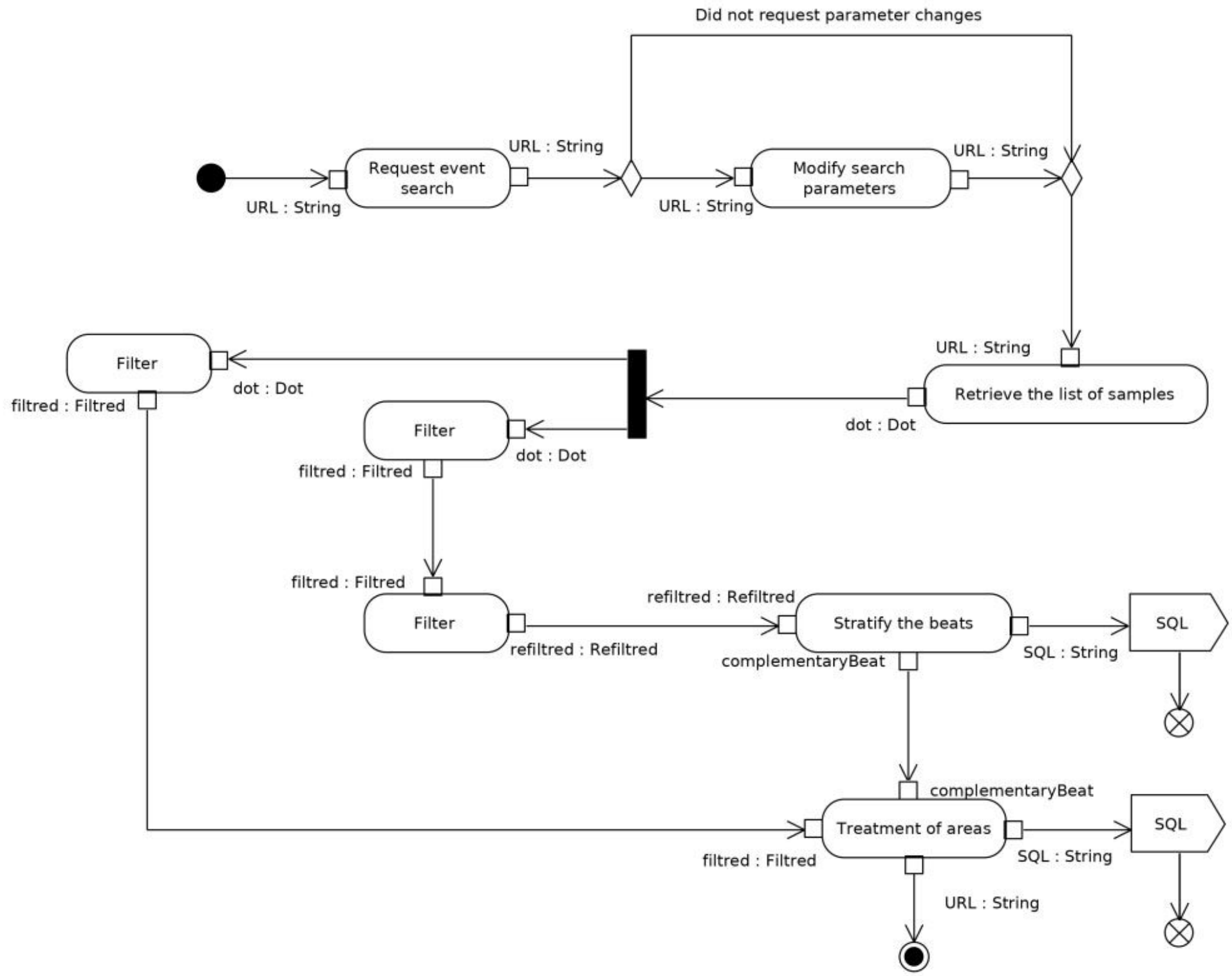

\section{Figure 2}

Activity diagram to detect ischemic episode. 


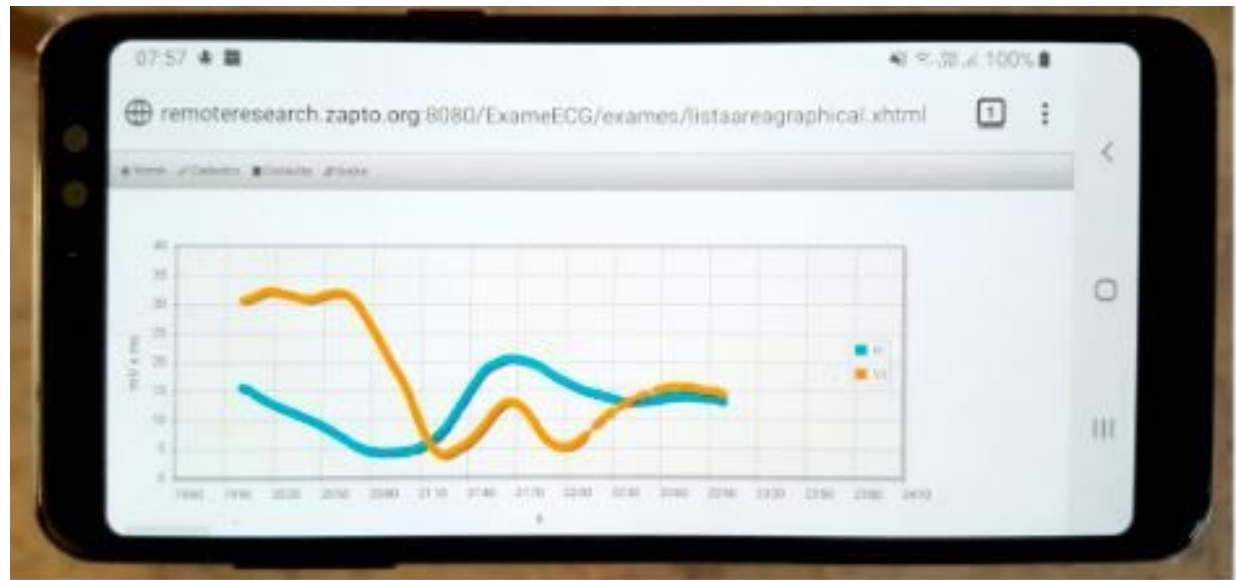

A

A Horne $>$ Regoter a Query pAbout

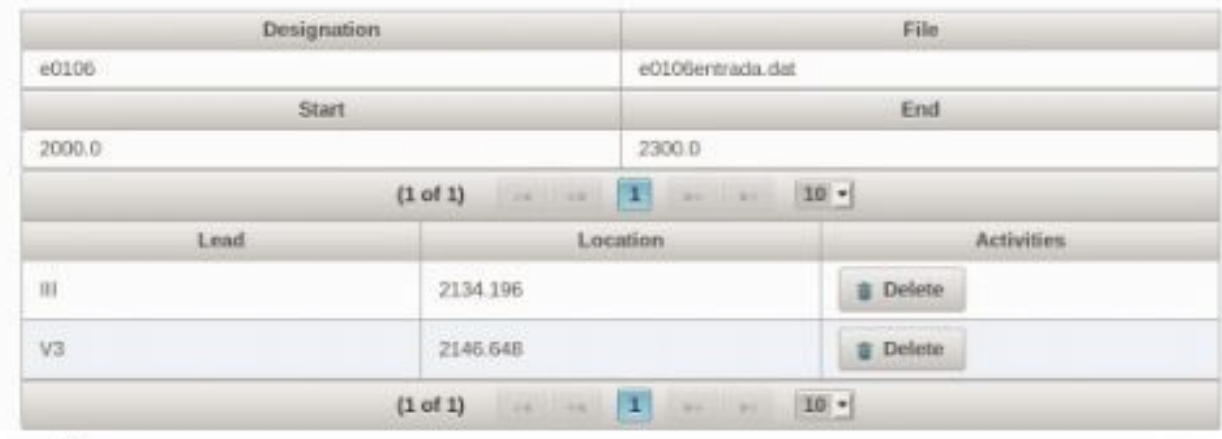

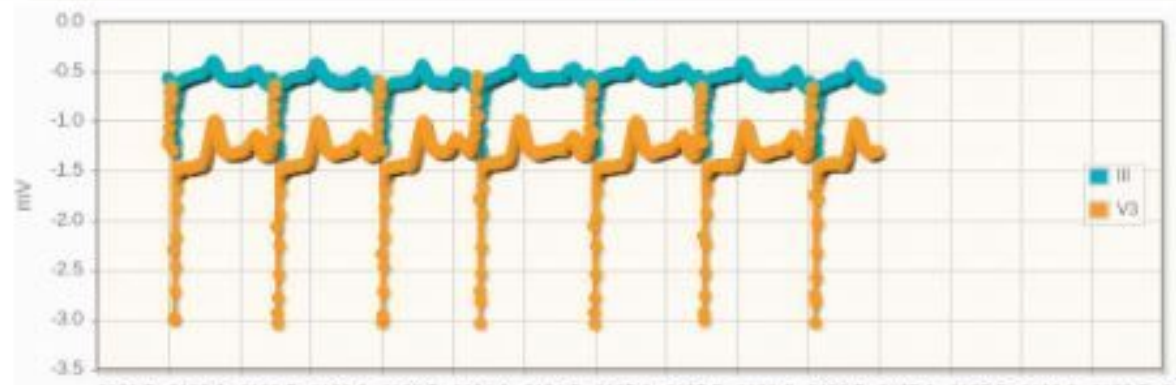

B

C

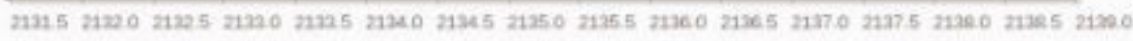

$\longrightarrow$

\section{Figure 3}

A - Graph of representative areas of beats for the entire range of two leads present in file e0106, displayed on a smartphone screen; B - Signs of the ischemic episode found in the interval; C Corresponding ECG graphs, where ST segment depression is quite evident in lead V3. 


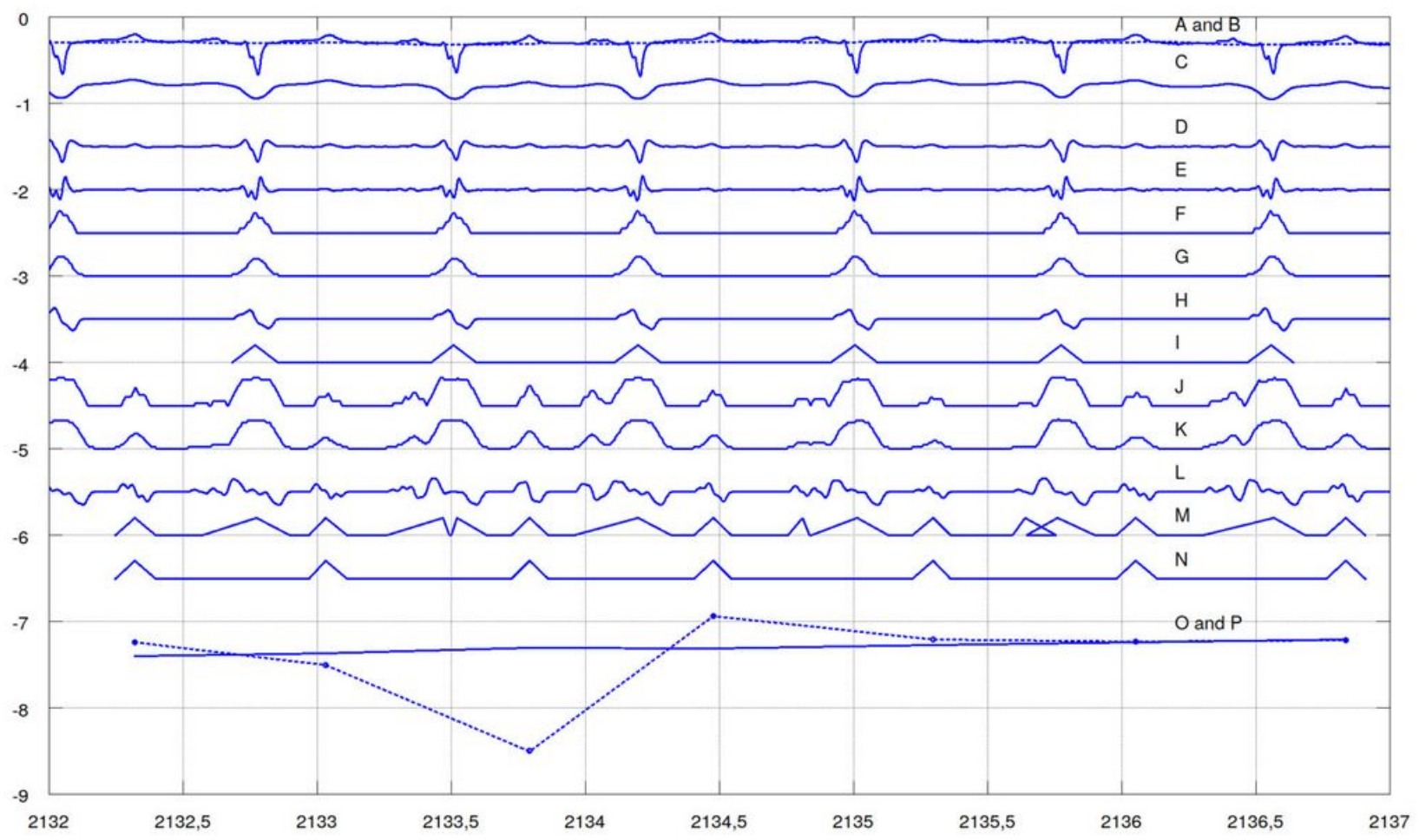

\section{Figure 4}

For the MLIII lead of the ECG given in file e0106, curves A and B represent, with amplitude adjustments, the lead and the isoelectric (dashed) curve in the range between $2132 \mathrm{~s}$ and $2137 \mathrm{~s}$, respectively. Then offset adjustments were also made to accommodate the curves: $\mathrm{C}$ - which is the result of a low-pass filter; D - after a high-pass and also a low- pass filter; E - derivative of D; F - histogram obtained from the derivative; $\mathrm{G}$ - result of a low-pass filter from the histogram; $\mathrm{H}$ derivative of the filtered histogram; I representation of the QRS complexes found; $J$ - a permissive limit histogram, applied to the curve $E$, sufficient to also find the ECG T waves; $\mathrm{K}$ - $\mathrm{J}$ low-pass filtering; $\mathrm{L}$ - derivative of $\mathrm{K} ; \mathrm{M}$ - the representation of all complexes and waves found; $\mathrm{N}$ representation of the $T$ waves found, separated from the other waves, using uniqueness, proximity and subsequence criteria; $\mathrm{O}$ - calculated areas for the ST segments; P - lowpass filtering interpolation curve of 0 . 


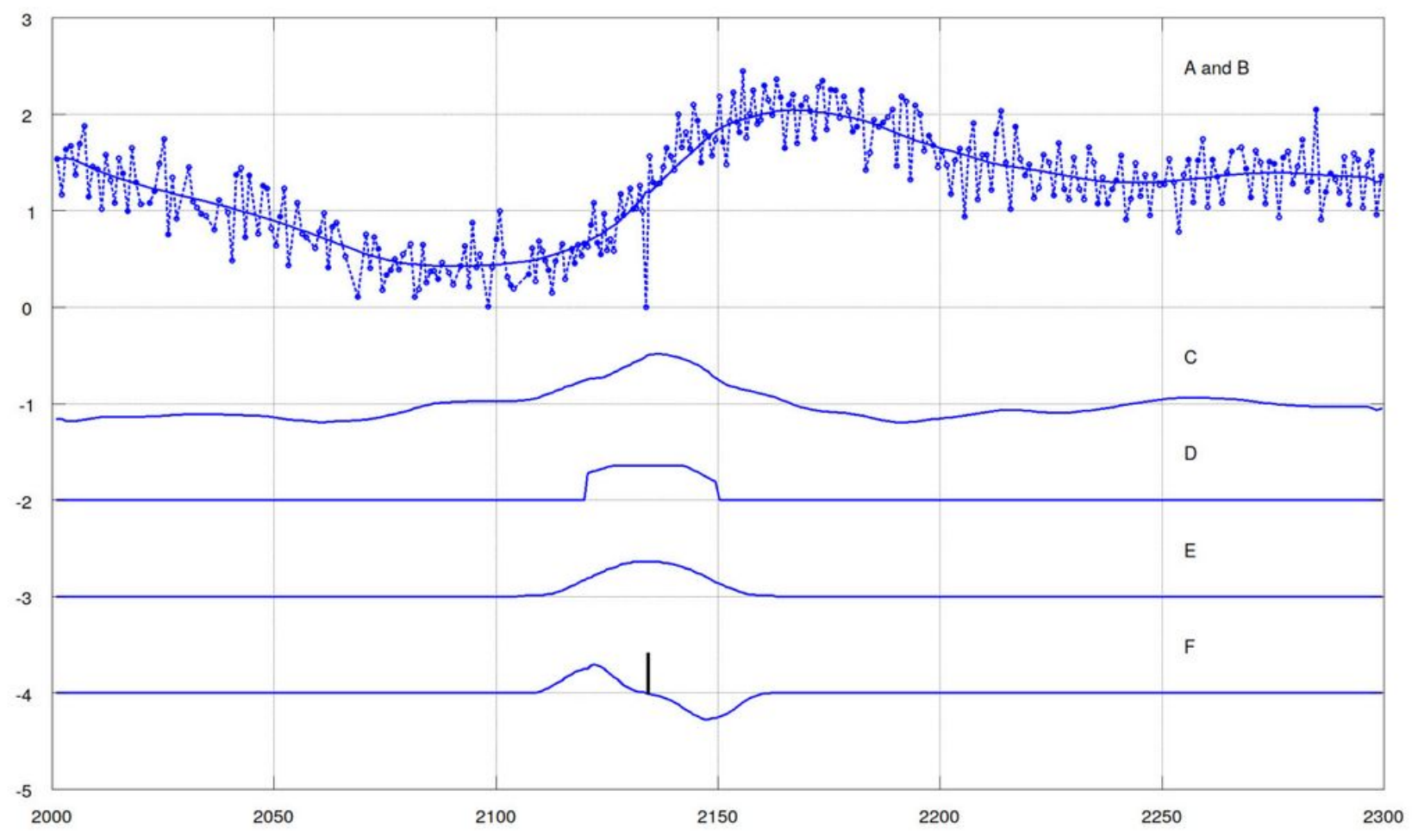

Figure 5

For the MLIII lead of the ECG given in file e0106 throughout the selected range of curve A, adjusted for its amplitude, represents the calculated areas for the ST segments; B - interpolation curve when applying a low-pass filter on A. In addition to adjusting the amplitudes, an offset was also used to accommodate the curves: $\mathrm{C}$ - derivative of $\mathrm{B} ; \mathrm{D}$ - histogram obtained from $\mathrm{C}$; $\mathrm{E}$ - lowpass histogram filtering and $\mathrm{F}$ derivative of $\mathrm{E}$, whose reading and application of the signal rule allows to find the moment of occurrence of a possible ischemia, shown in the curve. To account for a zero crossing only histograms that reach a positive threshold are considered.

\section{Supplementary Files}

This is a list of supplementary files associated with this preprint. Click to download.

- Table1.pdf

- Table2.pdf

- Table3.pdf 